\title{
Commentary: Double-outlet right ventricle revisited
}

\author{
Carl L. Backer, MD
}

\footnotetext{
From the Division of Cardiovascular-Thoracic Surgery, Ann \& Robert H. Lurie Children's Hospital of Chicago, Chicago, Ill; and Department of Surgery, Northwestern University Feinberg School of Medicine, Chicago, Ill. Disclosures: Dr Backer is a consultant to W. L. Gore \& Associates.

Received for publication July 31, 2019; accepted for publication July 31, 2019; available ahead of print Oct 3, 2019.

Address for reprints: Carl L. Backer, MD, Division of Cardiovascular-Thoracic Surgery, Ann \& Robert H. Lurie Children's Hospital of Chicago, 225 E Chicago Ave, mc 22, Chicago, IL 60611 (E-mail: cbacker@ luriechildrens.org).

J Thorac Cardiovasc Surg 2020;159:265 $0022-5223 / \$ 36.00$

Copyright (C) 2019 by The American Association for Thoracic Surgery

https://doi.org/10.1016/j.jtcvs.2019.07.126
}

In this issue of the Journal, Oladunjoye and colleagues, ${ }^{1}$ writing for the Boston group, have presented for us their extensive experience with double-outlet right ventricle (DORV). A thorough review of their results and strategies lends insight into the management of these children. For patients with DORV, there are important anatomic findings that help determine whether they should undergo primary or staged biventricular repair (as opposed to univentricular repair).

It appears that the ventricular septal defect (VSD) location remains one of the primary determinants of primary versus staged repair. Primary repair was possible in $88 \%$ of patients with a subpulmonary VSD, $79 \%$ of patients with a subaortic VSD, and $66 \%$ of patients with a doubly committed VSD. In contrast, only $37 \%$ of the patients with a noncommitted VSD underwent primary repair. This group with noncommitted VSD is actually a very interesting focus of the article, in that $35 \%$ of those patients had undergone a previous Glenn or Fontan operation. These are patients who were initially slated for a single-ventricle approach culminating in a Fontan procedure who then had conversion to a 2-ventricle repair. The other group of patients who mostly underwent staged repair were patients with pulmonary atresia, of whom only $30 \%$ underwent a primary repair.

One of the major points of this experience is that both approaches work by using the appropriate strategy for the appropriate anatomic condition. Oladunjoye and colleagues $^{1}$ in particular note that there is no reason to apologize for staging repair for these patients. In fact, they emphasize that the staged approach for the patients with more complex conditions (complete atrioventricular septal defect, D-transposed great vessels, elongated pathway of the left ventricle to the aorta, pulmonary atresia) helps to mitigate the operative mortality. The mean age at repair truly puts this in perspective. The mean age at repair for the primary biventricular repairs was 2.6 months. The mean age of the patients undergoing a staged approach was 29.8 months.

\section{Reference} 159:254-64.

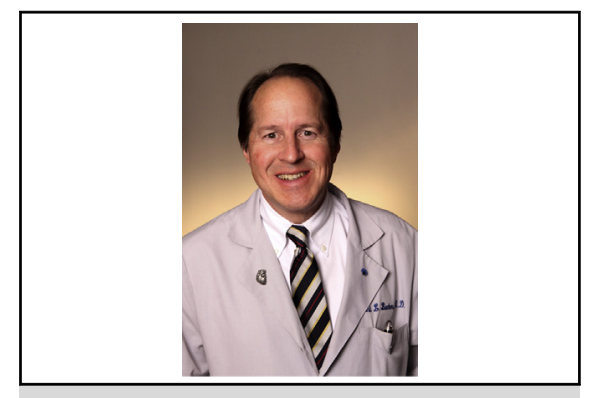

Carl L. Backer, MD

Central Message

In selected patients with double-outlet right ventricle, the outcomes of staged repair are not different from those of patients with less complex double-outlet right ventricle who have primary repair.

See Article page 254.

These strategies for DORV appear to have developed with time. Oladunjoye and colleagues ${ }^{1}$ note that their group previously found in their experience that baffling of the left ventricle to the aorta in neonates and infants with an elongated pathway of the left ventricle to the aorta had a high risk of left ventricular outflow tract obstruction. Oladunjoye and colleagues ${ }^{1}$ also note that there is a risk of third-degree atrioventricular block requiring pacemaker insertion if the VSD requires enlargement. This occurred in 12 patients, most of whom had noncommitted VSDs. Another (slightly confusing) point of clarification is that the patients who had a pulmonary artery band placed before biventricular repair are included in the primary repair group ( $n=30$ patients). One limitation of this review is that the denominator for this group of patients represents those patients who survived a biventricular repair.

This review of more than 200 patients with DORV undergoing biventricular repair adds substantially to our "database" of how to manage these patients. Certainly in almost all cardiac center conferences when discussing patients with DORV, there are strong opinions about how to manage these patients, and frequently there is much disagreement! This review may help "smooth the waters" and gives us evidence-based strategies for managing these patients.

1. Oladunjoye O, Piekarski B, Baird C, Banka P, Marx G, del Nido PJ, et al. Repair of double outlet right ventricle: midterm outcomes. J Thorac Cardiovasc Surg. 2020; 